\title{
Reduced expression of ASS is closely related to clinicopathological features and post-resectional survival of hepatocellular carcinoma
}

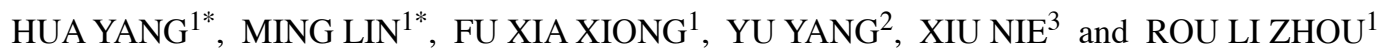 \\ Departments of ${ }^{1}$ Cell Biology and ${ }^{2}$ Pathology, School of Basic Medical Sciences, Peking University, \\ Beijing; ${ }^{3}$ Department of Pathology, Union Hospital Affiliated to Tongji Medical College, \\ Huazhong University of Science and Technology, Wuhan, P.R. China
}

Received April 2, 2009; Accepted August 26, 2009

DOI: 10.3892/ol_00000005

\begin{abstract}
Argininosuccinate synthetase (ASS) has previously been proven to be reductively expressed in hepatocellular carcinoma (HCC) and various types of HCC cell lines. Arginine, the product of ASS, has been used as a target in HCC by recombinant human arginase or arginine deiminase, which is now in the phase II clinical trial stage. This study aimed to present the levels of ASS expression in HCCs and its correlation with clinicopathological features and prognosis of HCC patients. Immunohistochemical detection of ASS was performed on samples from 71 patients with HCC. Positive staining was found in $21 \mathrm{HCCs}$, with a score of 2, as well as in normal liver tissues. Reduced ASS staining was found in 70.4\% (50/71) of HCC tissues, including 21 with a score of 0 and 29 with a score of 1 . The staining score in cancer tissues was significantly associated with gender, background liver, histopathological differentiation, recurrence, TNM staging and portal vein invasion $(\mathrm{P}<0.05)$, but not with age, viral status, tumor size and serum $\alpha$-fetoprotein level. Patients with a high ASS expression had significantly poorer overall and disease-free survival $(\mathrm{P}<0.001$ and $\mathrm{P}<0.001$, respectively). These data showed that ASS was reductively or negatively expressed in a large portion of $\mathrm{HCC}$, and that ASS levels in HCCs correlated inversely with prognosis. In conclusion, a high expression of ASS may be a novel marker of poor prognosis of patients presenting with HCC.
\end{abstract}

\section{Introduction}

Hepatocellular carcinoma (HCC), one of the most common fatal malignancies in many countries in Asia and Africa, is the

Correspondence to: Dr Rou Li Zhou, Department of Cell Biology, School of Basic Medical Sciences, Peking University, Beijing 100083, P.R. China

E-mail:rlzhou@bjmu.edu.cn

${ }^{*}$ Contributed equally

Key words: arginosuccinate synthetase, immunohistochemistry, hepatocellular carcinoma, survival leading cause of cancer mortality in China and its incidence is also increasing in Western countries (1). HCC is complex in etiology and pathogenesis (2). Risk factors include aflatoxin, alcohol, hepatitis B virus, hepatitis $\mathrm{C}$ virus and cirrhosis. Different risk factors lead to different molecular pathways, making the pathogenesis of HCC more complex to interpret $(3,4)$. Surgical resection provides an opportunity for cure, but the outcome of surgical HCC patients remains grave mainly due to frequent tumor recurrence (5-7). Other therapeutic strategies have a similar shortcoming. Although HCC prognosis depends on various elements, the biological characteristics of HCC are important. Thus, in order to aid in the prediction of prognosis or the selection of a therapeutic target, more potential markers should be explored.

Arginine is an indispensable amino acid to children, but one which is semi-essential to adults (8). Since 1930, arginine has been known to influence the growth of transplantable mice tumors (9). Argininosuccinate synthetase (ASS) is a key enzyme in the synthesis of arginine from citrulline and is present in all tissues and culture cells studied. This metabolic pathway allows cells to synthesize arginine from citrulline, making this amino acid non-essential for the growth of humans and most mammalian cells. It is well known that the highest ASS activity is found in the liver, where the enzyme is involved in the urea cycle and in the elimination of ammonia (10). Published studies showed HCC to be auxotrophic for arginine due to the lack of expression of ASS (11-14). However, the relationship between reduced levels of ASS expression in HCC tissues and its clinicopathological significance remains unclear.

The present study aimed to determine the relationship between the reduced level of ASS expression in HCC tissues by immunohistochemical detection (IHC) and the clinicopathological features and post-resectional survival. Our results suggested that the ASS staining score can be used as an independent marker for the prognosis of patients presenting with HCC.

\section{Materials and methods}

Patients. Tissue samples were obtained from 71 patients with $\mathrm{HCC}$ who underwent surgical resection in the Union Hospital 
Table I. Relationship between ASS expression and clinicopathological features of HCC.

\begin{tabular}{|c|c|c|c|c|c|}
\hline \multirow[b]{2}{*}{ Variables } & \multirow[b]{2}{*}{ Patients } & \multicolumn{3}{|c|}{ ASS expression } & \multirow[b]{2}{*}{ P-value } \\
\hline & & Low & Middle & High & \\
\hline All cases & 71 & 21 & 29 & 21 & \\
\hline Gender & & & & & 0.020 \\
\hline Male & 59 & 14 & 28 & 17 & \\
\hline Female & 12 & 7 & 1 & 4 & \\
\hline Age (years) & & & & & 0.787 \\
\hline$<60$ & 47 & 14 & 18 & 15 & \\
\hline$\geq 60$ & 24 & 7 & 11 & 6 & \\
\hline Background liver & & & & & 0.047 \\
\hline Normal liver & 3 & 1 & 2 & 0 & \\
\hline Chronic liver & 21 & 10 & 9 & 2 & \\
\hline Cirrhosis & 47 & 10 & 18 & 19 & \\
\hline Viral status & & & & & 0.237 \\
\hline Hepatitis virus B & 51 & 15 & 20 & 16 & \\
\hline Hepatitis virus $\mathrm{C}$ & 12 & 3 & 6 & 3 & \\
\hline Both hepatitis virus B and C & 2 & 0 & 0 & 2 & \\
\hline Non-B, Non-C & 6 & 3 & 3 & 0 & \\
\hline Tumor size & & & & & 0.630 \\
\hline$<5 \mathrm{~cm}$ & 38 & 13 & 15 & 10 & \\
\hline$\geq 5 \mathrm{~cm}$ & 33 & 8 & 14 & 11 & \\
\hline Portal vein invasion & & & & & $<0.001$ \\
\hline No & 52 & 21 & 21 & 10 & \\
\hline Yes & 19 & 0 & 8 & 11 & \\
\hline Histopathological differentiation & & & & & 0.008 \\
\hline Well-differentiated & 21 & 11 & 6 & 4 & \\
\hline Moderately differentiated & 26 & 8 & 13 & 5 & \\
\hline Poorly differentiated & 24 & 2 & 10 & 12 & \\
\hline Serum AFP level & & & & & 0.301 \\
\hline$<25 \mathrm{ng} / \mathrm{ml}$ & 35 & 13 & 14 & 8 & \\
\hline$\geq 25 \mathrm{ng} / \mathrm{ml}$ & 36 & 8 & 15 & 13 & \\
\hline TNM stage & & & & & $<0.001$ \\
\hline I-II & 25 & 18 & 6 & 1 & \\
\hline III-IV & 46 & 3 & 23 & 20 & \\
\hline Recurrence & & & & & 0.015 \\
\hline No & 17 & 9 & 7 & 1 & \\
\hline Yes & 54 & 12 & 22 & 20 & \\
\hline
\end{tabular}

ASS, arginosuccinate synthetase; HCC, hepatocellular carcinoma; AFP, $\alpha$-fetoprotein. ${ }^{a}$ Chi-square test.

Affiliated to Tongji Medical College from 2000 to 2002. The patients included 59 males and 12 females, with a median age of 49 years (range 33-74). The clinicopathological features of the patients including gender, age, background liver, viral status, tumor size, portal vein invasion, histopathological differentiation, serum $\alpha$-fetoprotein (AFP) level, TNM staging and recurrence of HCC are shown in Table I. The Institutional Ethics Committee approval for the project was obtained prior to the commencement of the study.
Immunohistochemical staining. ASS expression was detected immunohistochemically for paraffin-embedded specimens from 71 patients with HCC. Surgical specimens were formalin-fixed (10\%), paraffin-embedded and sectioned at $4 \mu \mathrm{m}$. For heat-induced epitope retrieval, deparaffinised sections were soaked in $10 \mathrm{mM}$ citrate buffer ( $\mathrm{pH} \mathrm{6.0)}$ and treated at $95^{\circ} \mathrm{C}$ for $30 \mathrm{~min}$ in a microwave oven. Immunohistochemical staining was performed using the avidin-biotin immunoperoxidase technique. Endogenous peroxidase activity was first 

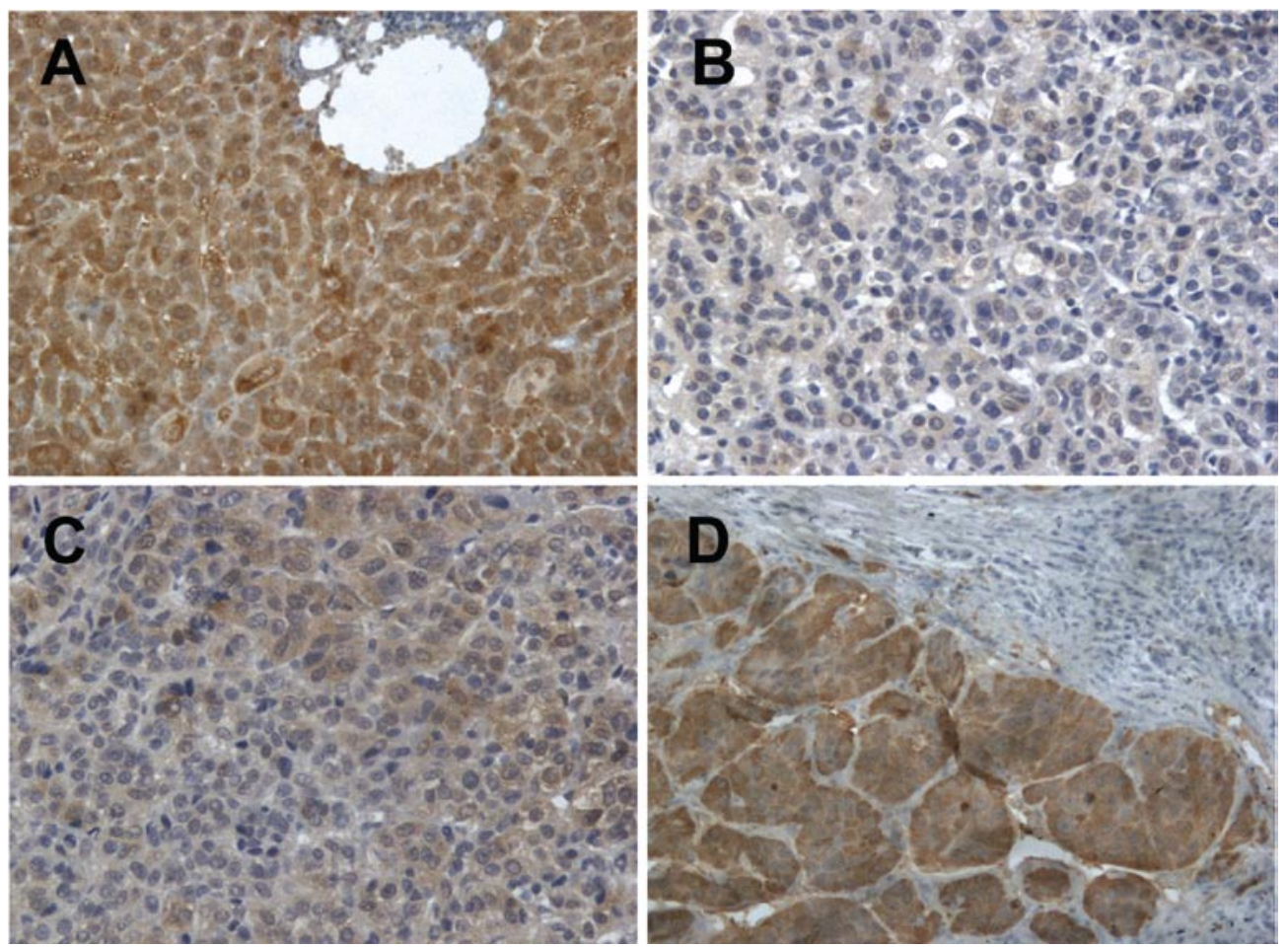

Figure 1. Representative staining pattern of ASS expression detected by IHC (positivity + intensity). (A) Normal liver tissue. (B, C and D) HCC tissues; B, score of $0+0 ; \mathrm{C}$, score of $1+1 ; \mathrm{D}$, score of $2+2$. Original magnification $\mathrm{x} 200$.

blocked by incubation with $0.3 \% \mathrm{H}_{2} \mathrm{O}_{2}$ in methanol for $15 \mathrm{~min}$. Non-specific immunoglobulin binding was then blocked by incubation with $10 \%$ normal goat serum for $10 \mathrm{~min}$. Sections were incubated at room temperature for $2 \mathrm{~h}$ with the anti-ASS monoclonal antibody (BD Pharmigen) at a 1:50 dilution. The sections were rinsed and incubated for $30 \mathrm{~min}$ with biotinylated second antibody. After washing, the sections were incubated for 30 min with horseradish peroxidase-conjugated streptavidin and treated with 3,3'-diaminobenzidine tetrahydrochloride in $0.01 \% \mathrm{H}_{2} \mathrm{O}_{2}$ for $10 \mathrm{~min}$. The slides were counterstained with Meyer's hematoxylin. As a negative control, the primary antibody was replaced with normal mouse IgG at an appropriate dilution.

Staining assessment and scoring. ASS expression levels were classified semi-quantitatively based on the total combined scores of the percentage of positively stained tumor cells together with the staining intensity. A tumor was scored as ' 0 ' if $<5 \%$ of tumor cells were stained positive, ' 1 ' if $5-50 \%$ were stained positive and ' 2 ' if $>50 \%$ of the cells were stained positive. The staining intensity was scored as ' 0 ' if no staining of cells occurred or if there was only weak staining, ' 1 ' if there was moderate staining and ' 2 ' in cases of strong staining. The final score of ASS expression was defined as 'low ASS expression' if the sum of the positivity score and the staining intensity score was 0-1, 'middle ASS expression' if the sum was 2 and 'high ASS expression' if the sum was 3-4. In each case, at least three different tumor areas were evaluated and the mean of the results was taken as the final expression score. The scoring procedure was carried out twice by two independent pathologists who had no knowledge of the clinical data and corresponding hematoxylin and eosin slides. The concordance rate between the two primary pathologists was $>95 \%$. In cases of significant disagreement, the slides in question were reviewed again simultaneously by the original two pathologists, together with a third pathologist, at a multiheaded microscope, in order to resolve the divergence of opinion.

Statistical analysis. The Chi-square test was used to show differences of categorical variables. Patient survival and differences were determined by the Kaplan-Meier method and log-rank test. Cox regression (proportional hazard model) was adopted for the multivariate analysis of prognostic factors. Statistical software package SPSS 11.5 (SPSS Inc., Chicago, IL) was employed for the analyses. $\mathrm{P}<0.05$ was defined as statistically significant.

\section{Results}

Clinical profiles of the patients. Tissue samples were obtained from 71 patients. Twenty-one $(29.6 \%)$ of the tissue samples were histopathologically well-differentiated, 26 (36.6\%) were moderately differentiated and $24(33.8 \%)$ were poorly differentiated. Portal vein invasion of the tumor cells occurred in $19(26.8 \%)$ of the 71 patients, but not in the remaining 52 (73.2\%) patients (Table I). Up to August 31, 2008 (the census date), 22 (31\%) patients were alive, while 49 (69\%) patients had succumbed to the disease. Follow-up ranged from 3 to 93 months (median 36 months).

ASS expression in HCC and its clinicopathological significance. A reduced ASS expression was detected in HCC 
Table II. Univariate survival analysis of overall and disease-free survival in 71 patients with HCC.

\begin{tabular}{|c|c|c|c|c|c|c|c|}
\hline \multirow[t]{2}{*}{ Variables } & \multirow[t]{2}{*}{ No. of cases } & \multicolumn{3}{|c|}{ OS } & \multicolumn{3}{|c|}{ DFS } \\
\hline & & $\begin{array}{c}\text { Mean } \pm S E \\
\text { (months) }\end{array}$ & $95 \% \mathrm{CI}$ & P-value ${ }^{a}$ & $\underset{\text { (months) }}{\text { Mean } \pm S E}$ & $95 \% \mathrm{CI}$ & P-value \\
\hline Gender & & & & 0.354 & & & 0.424 \\
\hline Male & 59 & $41 \pm 5$ & $(32-50)$ & & $34 \pm 5$ & $(25-43)$ & \\
\hline Female & 12 & $44 \pm 8$ & $(28-59)$ & & $40 \pm 8$ & $(25-55)$ & \\
\hline Age (years) & & & & 0.673 & & & 0.920 \\
\hline$<60$ & 47 & $42 \pm 5$ & $(32-52)$ & & $37 \pm 5$ & $(26-47)$ & \\
\hline$\geq 60$ & 24 & $38 \pm 6$ & $(27-50)$ & & $32 \pm 6$ & $(20-44)$ & \\
\hline Background liver & & & & 0.004 & & & 0.002 \\
\hline Normal liver & 3 & $69 \pm 4$ & $(62-77)$ & & $65 \pm 4$ & $(56-74)$ & \\
\hline Chronic liver & 21 & $62 \pm 8$ & $(46-78)$ & & $57 \pm 9$ & $(40-74)$ & \\
\hline Cirrhosis & 47 & $30 \pm 4$ & $(22-38)$ & & $23 \pm 4$ & $(16-31)$ & \\
\hline Viral status & & & & 0.120 & & & 0.273 \\
\hline Hepatitis virus B & 51 & $39 \pm 5$ & $(30-49)$ & & $33 \pm 5$ & $(23-42)$ & \\
\hline Hepatitis virus $\mathrm{C}$ & 12 & $41 \pm 10$ & $(20-61)$ & & $36 \pm 11$ & $(15-58)$ & \\
\hline Both hepatitis virus B and C & 2 & $19 \pm 10$ & $(0-37)$ & & $9 \pm 4$ & $(2-15)$ & \\
\hline Non-B, Non-C & 6 & $64 \pm 9$ & $(45-82)$ & & $55 \pm 10$ & $(37-74)$ & \\
\hline Tumor size & & & & 0.860 & & & 0.980 \\
\hline$<5 \mathrm{~cm}$ & 38 & $42 \pm 6$ & $(31-53)$ & & $35 \pm 6$ & $(24-46)$ & \\
\hline$\geq 5 \mathrm{~cm}$ & 33 & $42 \pm 6$ & $(30-54)$ & & $36 \pm 6$ & $(23-48)$ & \\
\hline Portal vein invasion & & & & $<0.001$ & & & $<0.001$ \\
\hline No & 52 & $54 \pm 5$ & $(44-64)$ & & $46 \pm 5$ & $(36-56)$ & \\
\hline Yes & 19 & $12 \pm 1$ & $(10-15)$ & & $7 \pm 1$ & $(5-10)$ & \\
\hline Histopathological differentiation & & & & 0.005 & & & 0.008 \\
\hline Well-differentiated & 21 & $60 \pm 8$ & $(44-75)$ & & $50 \pm 8$ & $(35-65)$ & \\
\hline Moderately differentiated & 26 & $42 \pm 6$ & $(29-54)$ & & $37 \pm 7$ & $(24-50)$ & \\
\hline Poorly differentiated & 24 & $25 \pm 5$ & $(15-36)$ & & $19 \pm 6$ & $(8-30)$ & \\
\hline Serum AFP level & & & & 0.516 & & & 0.397 \\
\hline$<25 \mathrm{ng} / \mathrm{ml}$ & 35 & $45 \pm 6$ & $(33-57)$ & & $39 \pm 6$ & $(27-51)$ & \\
\hline$\geq 25 \mathrm{ng} / \mathrm{ml}$ & 36 & $38 \pm 5$ & $(27-48)$ & & $31 \pm 6$ & $(20-42)$ & \\
\hline TNM stage & & & & $<0.001$ & & & $<0.001$ \\
\hline I-II & 25 & $75 \pm 6$ & $(63-87)$ & & $67 \pm 6$ & $(54-79)$ & \\
\hline III-IV & 46 & $25 \pm 4$ & $(18-32)$ & & $19 \pm 4$ & $(12-26)$ & \\
\hline ASS expression & & & & $<0.001$ & & & $<0.001$ \\
\hline Low & 21 & $75 \pm 6$ & $(64-86)$ & & $66 \pm 6$ & $(54-77)$ & \\
\hline Middle & 29 & $35 \pm 6$ & $(24-47)$ & & $31 \pm 6$ & $(19-43)$ & \\
\hline High & 21 & $17 \pm 4$ & $(10-25)$ & & $11 \pm 4$ & $(3-19)$ & \\
\hline
\end{tabular}

ASS, arginosuccinate synthetase; HCC, hepatocellular carcinoma; OS, overall survival; DFS, disease-free survival; AFP, $\alpha$-fetoprotein. ${ }^{2}$ Log-rank test.

tissues obtained from 50 patients $(70.4 \%)$ in accordance with the aforementioned criteria. Normal liver tissue as a control exhibited positive staining (Fig. 1A) with 21, 29 and $21 \mathrm{HCC}$ samples exhibiting staining scores of 0,1 and 2, respectively (Fig. 1B-D). The staining scores were significantly associated with gender, background liver, histopathological differentiation, recurrence, TNM staging and portal vein invasion of HCC (Table I; $\mathrm{P}<0.05$ ), but not with age, viral status, tumor size and serum AFP level of the tumor antigen marker (Table I; $\mathrm{P}>0.05)$.

Factors influencing overall or disease-free survival of HCC patients after tumor resection. Using the Kaplan-Meier method and log-rank test, HCC tissues with a higher staining score of ASS were correlated with a shorter overall or disease-free survival of patients (Table II, Fig. 2A and B; log-rank value 33.00 
Table III. Multivariate survival analysis of overall and disease-free survival in 71 patients with HCC.

\begin{tabular}{|c|c|c|c|c|c|c|}
\hline \multirow[t]{2}{*}{ Variables } & \multicolumn{3}{|c|}{ OS } & \multicolumn{3}{|c|}{ DFS } \\
\hline & $\mathrm{RR}$ & $95 \%$ CI & P-value ${ }^{a}$ & RR & $95 \%$ CI & P-value \\
\hline TNM stage & 2.246 & $(0.834-7.234)$ & 0.103 & 2.398 & $(0.841-6.837)$ & 0.102 \\
\hline Background liver & 0.934 & $(0.479-1.823)$ & 0.842 & 1.387 & $(0.768-2.507)$ & 0.278 \\
\hline Portal vein invasion & 3.052 & $(1.507-6.179)$ & 0.002 & 2.258 & (1.085-4.698) & 0.029 \\
\hline $\begin{array}{l}\text { Histopathological } \\
\text { differentiation }\end{array}$ & 1.401 & $(0.903-2.172)$ & 0.004 & 1.469 & $(0.923-2.337)$ & 0.105 \\
\hline ASS expression & 2.139 & $(1.283-3.568)$ & 0.004 & 1.880 & $(1.128-3.133)$ & 0.015 \\
\hline
\end{tabular}

ASS, arginosuccinate synthetase; HCC, hepatocellular carcinoma; OS, overall survival; DFS, disease-free survival; RR, relative risk; CI, confidence interval. aCox regression test.
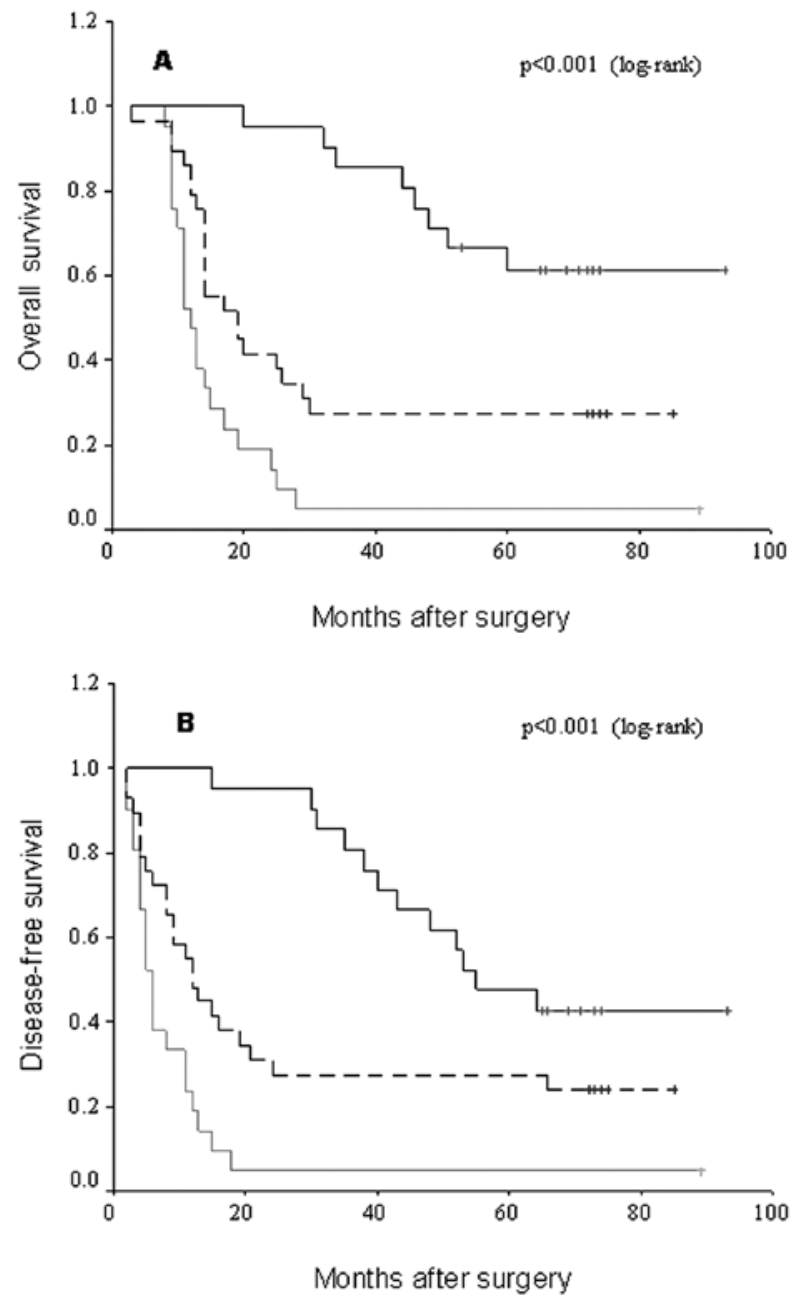

Figure 2. Comparison of survival of patients with HCC after resection based on staining scores of ASS. Score 0 , black solid line; score 1, black dashed line; score 2, gray solid line. (A) Overall and (B) disease-free survival after resection.

and 27.72; $\mathrm{P}<0.001$ and $\mathrm{P}<0.001$, respectively). Survival benefits were found in patients with earlier TNM staging, a higher histopathological differentiation grade, absence of portal vein invasion and a better background liver for overall or diseasefree survival (Table II; $\mathrm{P}<0.05$ ), whereas other patients showed no predictive values (Table II; P>0.05). The above-mentioned significant parameters were included in a multivariate Cox regression analysis which revealed that the ASS staining score (RR, 2.139; 95\% CI, 1.283-3.568; $\mathrm{P}=0.004)$, portal vein invasion (RR, 3.052; 95\% CI, 1.507-6.179; $\mathrm{P}=0.002)$ and histopathological differentiation ( $\mathrm{RR}, 1.401$; 95\% CI, 0.903-2.172; $\mathrm{P}=0.004$ ) were independent prognostic markers for overall survival of patients with HCC (Table III; P<0.05). On the other hand, the ASS staining score (RR, 1.880; 95\% CI, 1.128-3.133; $\mathrm{P}=0.015)$ and portal vein invasion $(\mathrm{RR}, 2.258$; 95\% CI, 1.085-4698; $\mathrm{P}=0.029)$ were independent prognostic markers for disease-free survival of patients with HCC (Table III; $\mathrm{P}<0.05$ ).

\section{Discussion}

ASS is a key enzyme which converts citrulline to arginine. Tumors which usually express reduced ASS include hepatocellular carcinoma, melanoma, some mesotheliomas and some renal cell cancer types $(11,14-19)$. To the best of our knowledge, this is the first study concerning ASS expression levels detected by IHC and its prognostic significance for HCC patients. Our results suggested that ASS is reductively expressed in a large portion (70.4\%) of HCC tissues with a staining score of 0 or 1 . Moreover, the magnitude of down-regulated expression correlated with better prognosis, especially for the staining score of 0 . A reduced ASS expression predicts the same clinical value as early TNM staging, rare portal vein invasion and a reduced possibility of recurrence.

As previously reported, depletion of arginine causes substantial havoc to cells, in particular tumor cells (13). Due to their rapid proliferation, tumor cells require amino acids as nutrients. Specifically, arginine is the first amino acid that is exhausted and depleted faster than any other nutrient by normal cell metabolism, but exhibits low recycling efficiency (20). When arginine was depleted, favorable conditions were anticipated prior to the resumption of normal cell division. However, tumor cells, with their cell cycle aberrations, continued to progress with the cell cycle despite the absence of arginine, leading to a gross imbalance and cell death (20). Based on this fact, a strategy to degrade arginine was developed to cure ASS (-) tumors because ASS-expressed normal cells produce arginine from citrulline, whereas ASS (-) tumor 
cells cannot. Several enzymes, including human arginase and arginine deiminase (ADI) which is a microbial enzyme from mycoplasma spp, are currently in phase II clinical trials (21-23). These enzymes have a high affinity to arginine and catalyze the degradation of arginine. It was reported that ADI activated anti-proliferation on a number of malignant cells in vitro and anti-tumor effects in vivo (15). The extent of ADI anti-proliferation depends on the endogenous activity of ASS, the rate-limiting enzyme involved in the recycling of citrulline into arginine. However, arginine depletion can induce ASS expression in certain melanoma cell lines which can lead to in vitro drug resistance (13).

A reduced expression of ASS in cancer cells and its higher expression in the normal liver cells of HCC patients suggested that only cancer cells are auxotrophic for arginine. Thus, ADI was able to exert its anti-tumor activity without any adverse effect on surrounding normal liver cells (16). ASS is the ratelimiting enzyme in the conversion of citrulline to arginine for ammonia detoxification through the urea cycle in the liver. A probable explanation for the loss of ASS activity in HCC is cellular dedifferentiation which may occur during tumorigenesis. Since dedifferentiation is a regressive process of cells to a primitive embryonic state, it may be related to a decrease of ASS expression in the neonatal level of liver. Thus, the level of ASS remains low during the fetal period in the liver $(16,24)$. Another explanation involves the down-regulation of ASS gene expression at the transcriptional level by its promoter methylation (14).

HCC remains a troublesome malignancy with poor prognosis, due to its strong drug resistance to conventional cancer treatments, as well as its frequent metastasis and recurrence. In spite of extensive research and various therapies, a molecular marker needs to be found that can be used as a target for the treatment of HCC. The current study provided a novel candidate, ASS, as a molecular marker of both the biological behaviors and surgical outcome of HCC. Measurement by IHC of a reduced ASS expression was closely correlated with better prognosis and allowed for a prediction of post-resectional survival.

Taken together, ASS in cancer tissues was reductively expressed in numerous patients presenting with HCC. ASS had a direct correlation with cancer differentiation, TNM staging, portal vein invasion and recurrence, as well as the overall and disease-free survival of patients with HCC. Therefore, we concluded that ASS may be a novel marker for predicting prognosis of patients presenting with $\mathrm{HCC}$, and suggest that ASS be used as a target for the treatment of HCC. In order to improve therapy for HCC, more studies need to be conducted in order for ASS expression or activity in tumor cells to be attenuated.

\section{References}

1. Bosch FX, Ribes J, Cleries R and Diaz M: Epidemiology of hepatocellular carcinoma. Clin Liver Dis 9: 191-211, 2005.

2. Farazi PA and DePinho RA: The genetic and environmental basis of hepatocellular carcinoma. Discov Med 6: 182-186, 2006.

3. Farazi PA and DePinho RA: Hepatocellular carcinoma pathogenesis: from genes to environment. Nat Rev 6: 674-687, 2006.

4. Suriawinata A and Xu R: An update on the molecular genetics of hepatocellular carcinoma. Semin Liver Dis 24: 77-88, 2004.
5. Tanaka S, Mogushi K, Yasen M, Noguchi N, Kudo A, Kurokawa T, Nakamura N, Inazawa J, Tanaka $\mathrm{H}$ and Arii S: Surgical contribution to recurrence-free survival in patients with macrovascular-invasion-negative hepatocellular carcinoma. J Am Coll Surg 208: 368-374, 2009.

6. Kamiyama T, Nakanishi K, Yokoo H, Kamachi H, Tahara M, Suzuki T, Shimamura T, Furukawa H, Matsushita M and Todo S: Recurrence patterns after hepatectomy of hepatocellular carcinoma: implication of Milan criteria utilization. Ann Surg Oncol 16: 1560-1571, 2009.

7. Kaibori M, Ishizaki M, Saito T, Matsui K, Kwon AH and Kamiyama Y: Risk factors and outcome of early recurrence after resection of small hepatocellular carcinomas. Am J Surg 198: 39-45, 2009.

8. Grabon W: Arginine as a crucial amino acid in carcinogenesis and tumor growth. Postepy Hig Med Dosw 60: 483-489, 2006.

9. Wu G and Morris SM Jr: Arginine metabolism: nitric oxide and beyond. J Biochem 336: 1-17, 1998.

10. Husson A, Brasse-Lagnel C, Fairand A, Renouf S and Lavoinne A: Argininosuccinate synthetase from the urea cycle to the citrulline-NO cycle. Eur J Biochem 270: 1887-1899, 2003.

11. Cheng PN, Lam TL, Lam WM, Tsui SM, Cheng AW, Lo WH and Leung YC: Pegylated recombinant human arginase (rhArgpeg5,000 mw) inhibits the in vitro and in vivo proliferation of human hepatocellular carcinoma through arginine depletion. Cancer Res 67: 309-317, 2007.

12. Wheatley DN and Campbell E: Arginine catabolism, liver extracts and cancer. Pathol Oncol Res 8: 18-25, 2002.

13. Feun L, You M, Wu CJ, Kuo MT, Wangpaichitr M, Spector S and Savaraj N: Arginine deprivation as a targeted therapy for cancer. Curr Pharm Des 14: 1049-1057, 2008.

14. Dillon BJ, Prieto VG, Curley SA, Ensor CM, Holtsberg FW, Bomalaski JS and Clark MA: Incidence and distribution of argininosuccinate synthetase deficiency in human cancers: a method for identifying cancers sensitive to arginine deprivation. Cancer 100: 826-833, 2004.

15. Ensor CM, Holtsberg FW, Bomalaski JS and Clark MA: Pegylated arginine deiminase (ADI-SS PEG20,000 mw) inhibits human melanomas and hepatocellular carcinomas in vitro and in vivo. Cancer Res 62: 5443-5450, 2002.

16. Yoon CY, Shim YJ, Kim EH, Lee JH, Won NH, Kim JH, Park IS, Yoon DK and Min BH: Renal cell carcinoma does not express argininosuccinate synthetase and is highly sensitive to arginine deprivation via arginine deiminase. Int J Cancer 120: 897-905, 2007.

17. Bowles TL, Kim R, Galante J, Parsons CM, Virudachalam S, Kung HJ and Bold RJ: Pancreatic cancer cell lines deficient in argininosuccinate synthetase are sensitive to arginine deprivation by arginine deiminase. Int J Cancer 123: 1950-1955, 2008.

18. Park H, Lee JB, Shim YJ, Shin YJ, Jeong SY, Oh J, Park GH, Lee KH and Min BH: Arginine deiminase enhances MCF-7 cell radiosensitivity by inducing changes in the expression of cell cycle-related proteins. Mol Cell 25: 305-311, 2008.

19. Kim JH, Kim JH, Yu YS, Kim DH, Min BH and Kim KW: Antitumor activity of arginine deiminase via arginine deprivation in retinoblastoma. Oncol Rep 18: 1373-1377, 2007.

20. Scott L, Lamb J, Smith S and Wheatley DN: Single amino acid (arginine) deprivation: rapid and selective death of cultured transformed and malignant cells. Br J Cancer 83: 800-810, 2000.

21. Ascierto PA, Scala S, Castello G, Daponte A, Simeone E, Ottaiano A, Beneduce G, De Rosa V, Izzo F, Melucci MT, Ensor CM, Prestayko AW, Holtsberg FW, Bomalaski JS, Clark MA, Savaraj N, Feun LG and Logan TF: Pegylated arginine deiminase treatment of patients with metastatic melanoma: results from phase I and II studies. J Clin Oncol 23: 7660-7668, 2005.

22. Izzo F, Marra P, Beneduce G, Castello G, Vallone P, De Rosa V, Cremona F, Ensor CM, Holtsberg FW, Bomalaski JS, Clark MA, $\mathrm{Ng} \mathrm{C}$ and Curley SA: Pegylated arginine deiminase treatment of patients with unresectable hepatocellular carcinoma: results from phase I/II studies. J Clin Oncol 22: 1815-1822, 2004.

23. Takaku H, Matsumoto M, Misawa S and Miyazaki K: Anti-tumor activity of arginine deiminase from Mycoplasma argini and its growth-inhibitory mechanism. Jpn J Cancer Res 86: 840-846, 1995.

24. Hurwitz R and Kretchmer N: Development of arginine-synthesizing enzymes in mouse intestine. Am J Physiol 251: 103-110, 1986. 